\title{
Adipose tissue macrophages induce hepatic neutrophil recruitment and macrophage accumulation in mice
}

Citation for published version (APA):

Bijnen, M., Josefs, T., Cuijpers, I., Maalsen, C. J., van de Gaar, J., Vroomen, M., Wijnands, E., Rensen, S. S., Greve, J. W. M., Hofker, M. H., Biessen, E. A. L., Stehouwer, C. D. A., Schalkwijk, C. G., \& Wouters, K. (2018). Adipose tissue macrophages induce hepatic neutrophil recruitment and macrophage accumulation in mice. Gut, 67(7), 1317-1327. https://doi.org/10.1136/gutjnl-2016-313654

Document status and date:

Published: 01/07/2018

DOI:

10.1136/gutjnl-2016-313654

Document Version:

Publisher's PDF, also known as Version of record

Document license:

Taverne

Please check the document version of this publication:

- A submitted manuscript is the version of the article upon submission and before peer-review. There can be important differences between the submitted version and the official published version of record.

People interested in the research are advised to contact the author for the final version of the publication, or visit the DOI to the publisher's website.

- The final author version and the galley proof are versions of the publication after peer review.

- The final published version features the final layout of the paper including the volume, issue and page numbers.

Link to publication

\footnotetext{
General rights rights.

- You may freely distribute the URL identifying the publication in the public portal. please follow below link for the End User Agreement:

www.umlib.nl/taverne-license

Take down policy

If you believe that this document breaches copyright please contact us at:

repository@maastrichtuniversity.nl

providing details and we will investigate your claim.
}

Copyright and moral rights for the publications made accessible in the public portal are retained by the authors and/or other copyright owners and it is a condition of accessing publications that users recognise and abide by the legal requirements associated with these

- Users may download and print one copy of any publication from the public portal for the purpose of private study or research.

- You may not further distribute the material or use it for any profit-making activity or commercial gain

If the publication is distributed under the terms of Article $25 \mathrm{fa}$ of the Dutch Copyright Act, indicated by the "Taverne" license above, 


\title{
Adipose tissue macrophages induce hepatic neutrophil recruitment and macrophage accumulation in mice
}

\author{
Mitchell Bijnen, ${ }^{1,2}$ Tatjana Josefs, ${ }^{1,2,3}$ |lona Cuijpers, ${ }^{1,2}$ Constantijn J Maalsen, 1,2 \\ José van de Gaar, ${ }^{1,2}$ Maria Vroomen, 1,2 Erwin Wijnands, 2,4 Sander S Rensen, 2,5 \\ Jan Willem M Greve, ${ }^{6}$ Marten H Hofker, ${ }^{7}$ Erik A L Biessen, ${ }^{2,4}$ Coen D A Stehouwer, ${ }^{1,2}$ \\ Casper G Schalkwijk, ${ }^{1,2}$ Kristiaan Wouters ${ }^{1,2}$
}

\begin{abstract}
- Additional material is published online only. To view please visit the journal online (http://dx.doi.org/10.1136/ gutjnl-2016-313654).

For numbered affiliations see end of article.

\section{Correspondence to Dr Kristiaan Wouters, Department of Internal Medicine, Maastricht University, Maastricht, PO box 616 (UNS50/14) 6200MD, The Netherlands; kristiaan wouters@maastrichtuniversity. $\mathrm{nl}$}

Professor Marten H Hofker is deceased.

Received 23 December 2016 Revised 29 September 2017 Accepted 2 October 2017 Published Online First 26 October 2017

\section{Linked}

- http://dx.doi.org/10.1136/ gutjnl-2017-315393

Check for updates

To cite: Bijnen M, Josefs T, Cuijpers I, et al. Gut

2018:67:1317-1327.

\section{ABSTRACT}

Objective Obesity is a risk factor for non-alcoholic steatohepatitis (NASH). This risk has been attributed to visceral adipose tissue (VAT) expansion associated with increased proinflammatory mediators. Accumulation of $\mathrm{CD}_{11 \mathrm{C}^{+}}$proinflammatory adipose tissue macrophages (ATM) is an important driver of vAT inflammation. We investigated the role of ATMs in hepatic inflammation during NASH development.

Design VAT isolated from lean, obese or ATM -depleted (using clodronate liposomes) obese mice was transplanted to lean $\mathrm{Idlr}^{-/}$acceptor mice. Systemic and hepatic inflammation was assessed either after 2 weeks on standard chow or after 8 weeks on high cholesterol diet (HCD) to induce NASH.

Results Transplanting donor vAT from obese mice increased HCD-induced hepatic macrophage content compared with lean-transplanted mice, worsening liver damage. ATM depletion prior to VAT transplantation reduced this increased hepatic macrophage accumulation. On chow, vAT transplantation induced a more pronounced increase in circulating and hepatic neutrophil numbers in obese-transplanted than lean-transplanted mice, while ATM depletion prior to vAT transplantation reversed this effect. Microarray analysis of fluorescence-activated cell sorting of CD11 $\mathrm{c}^{+}$and CD11 $\mathrm{C}^{-}$macrophages isolated from donor adipose tissue showed that obesity resulted in enhanced expression of neutrophil chemotaxis genes specifically in CD11 $\mathrm{c}^{+}$ ATMs. Involvement of the neutrophil chemotaxis proteins, CXCL14 and CXCL16, was confirmed by culturing vAT. In humans, CD11c expression in VAT of obese individuals correlated with vAT expression of neutrophil chemotactic genes and with hepatic expression of neutrophil and macrophage marker genes.

Conclusion ATMs from obese vAT induce hepatic macrophage accumulation during NASH development, possibly by enhancing neutrophil recruitment.

\section{INTRODUCTION}

Obesity has become a major health burden and is considered a key risk factor for diseases such as diabetes, non-alcoholic fatty liver disease (NAFLD) and a plethora of cardiovascular diseases (CVD). ${ }^{12}$ This increased risk has been mainly attributed to the expansion of visceral adipose tissue (vAT), which is associated with inflammation. Lipid accumulation in the liver, known as steatosis, is present in the majority of obese subjects, of which 30\% have biopsy-proven non-alcoholic steatohepatitis (NASH). ${ }^{3}$ NASH is the most progressive form of NAFLD and is characterised by steatosis accompanied by inflammation causing irreversible liver damage and hepatic fibrosis. Extensive fibrosis can lead to cirrhosis, requiring patients to undergo a liver transplantation. Moreover, hepatic inflammation increases the risk of developing hepatocellular carcinoma and increases CVD risk. ${ }^{45}$ Hepatic macrophages or Kupffer cells play a major role in liver inflammation and are thought to be triggered by an abundance of liver fat and factors such as inflammatory cytokines, oxidative stress, advanced glycation end-products and cholesterol. ${ }^{67}$ However, the exact triggers of hepatic inflammation are not yet understood.

Compared with other adipose tissue (AT) depots, vAT is considered the main contributor to NAFLD development. Due to its anatomic proximity to the liver and due to the fact that venous drainage from vAT happens via the portal system, vAT could directly deliver fatty acids and inflammatory mediators to the liver. ${ }^{8}$ Moreover, portal drainage of AT grafts has been shown to influence insulin sensitivity, possibly affecting NAFLD development. ${ }^{9}$ Furthermore, the chronic systemic inflammation associated with vAT expansion may also contribute to hepatic inflammation. During obesity, adipose tissue macrophages (ATM) accumulate in the vAT of mice and humans. ${ }^{10} 11$ In addition to their elevated numbers, ATM phenotype changes during obesity development. vAT from lean subjects typically contains more mannose receptor C-type 1 positive $\left(\mathrm{MRC1}^{+}\right) \mathrm{CD}^{-} 1 \mathrm{c}^{-}$macrophages frequently described as 'alternatively activated' anti-inflammatory M2 macrophages. In comparison, vAT from obese individuals has an abundance of 'classically activated' proinflammatory CD11c ${ }^{+} \mathrm{M} 1$ macrophages, which produce high levels of TNF, $i N O S$ and $I L 12$. CD $11 c^{+}$macrophages are typically found in crown-like structures surrounding dead adipocytes, are associated with insulin resistance and may contribute to systemic chronic inflammation. ${ }^{10}$ However, whether CD $11 \mathrm{c}^{+}$macrophages directly 
Significance of this study

What is already known on this subject?

- Obesity is characterised by adipose tissue dysfunction resulting in increased adipose tissue inflammation, which can cause systemic inflammation.

- Obese adipose tissue is rich in $\mathrm{CD} 11 \mathrm{c}^{+}$macrophages which are proinflammatory and contribute to adipose tissue inflammation.

- A positive association between visceral adipose tissue (vAT) macrophage numbers and liver histopathology (steatosis, fibrosis and inflammation score) has been shown in morbidly obese subjects.

\section{What are the new findings?}

- The proinflammatory $\mathrm{CD} 11 \mathrm{c}^{+}$macrophages that accumulate in obese adipose tissue express high levels of neutrophil chemotaxis genes resulting in elevated secretion of neutrophil chemotaxis proteins, such as CXCL14 and CXCL16, by obese adipose tissue.

- The CD11 ${ }^{+}$adipose tissue macrophages recruit neutrophils from bone marrow resulting in elevated circulating neutrophil levels and consequently increased hepatic neutrophil accumulation.

- In an experimental model of non-alcoholic steatohepatitis (NASH), transplanting obese adipose tissue caused increased hepatic macrophage accumulation worsening liver damage.

- CD11c expression, as a marker of proinflammatory macrophages, was associated with neutrophil chemotaxis gene expression in human vAT biopsies. In addition, vAT CD11c expression also correlated with gene expression of neutrophil and macrophage markers in paired human liver biopsies.

\section{How might it impact on clinical practice in the foreseeable} future?

- Our data again show the need to tackle adipose tissue inflammation as it seemingly contributes directly to complications such as NASH. More awareness regarding this subject is necessary and medication targeting systemic inflammation might be a treatment option.

- By revealing targetable proteins involved in the initiation of hepatic inflammation in obesity, such as the proposed neutrophil chemotaxis genes, specific inhibitors could be developed that might prevent effects of adipose tissue inflammation on systemic inflammation and thus the liver.

- For definitive diagnosis of NASH, an invasive liver biopsy is currently still required. Measuring a panel of circulating inflammatory proteins (chemokines) linked to hepatic inflammation would be a vast improvement.

contribute to NASH is unknown. Tordjman et al demonstrated a positive association between visceral ATM numbers and liver histopathology (steatosis, fibrosis and inflammation score) in morbidly obese subjects. ${ }^{12}$ However, which macrophage subset underlies this association and whether macrophages are causally linked to NASH development is unknown. In the current study, we investigated whether ATMs directly cause hepatic inflammation during NASH development. To achieve this, lean mice were transplanted with vAT from either lean donor mice, obese donor mice or obese donor mice from which ATMs in vAT tissue were depleted prior to transplantation. This experimental set-up allowed us to investigate whether hepatic inflammation was affected by transplanting AT of obese mice compared with transplanting AT of lean mice. In addition, the exact contribution of
ATMs was assessed by depleting ATMs prior to transplantation. Our study reveals a key role of ATMs in hepatic inflammation by amplifying macrophage accumulation in established NASH, possibly via inducing early neutrophil infiltration.

\section{MATERIALS AND METHODS}

Additional materials and methods are included in the online supplementary information.

\section{AT transplantation}

Epididymal AT derived from male donor C57BL/6 $\mathrm{ddll}^{-/-} \mathrm{CD} 45.1$ mice fed a low-fat diet (LFD), high-fat diet (HFD) or HFD in combination with clodronate liposomes injection was transplanted to male C57BL/6 CD45.2 congenic ldlr ${ }^{-/}$mice resulting in three groups: lean-transplanted acceptors (LTA), obese-transplanted acceptors (OTA) and ATM-depleted obese-transplanted acceptors (DOTA). In the first experiment, hepatic steatosis and inflammation were induced in $\mathrm{ldlr}^{-/-}$acceptor mice with a high-cholesterol diet (HCD) for 4 weeks before and 8 weeks after AT transplantation. ${ }^{13}{ }^{14}$ In the second experiment, all acceptor mice received standard chow for 2 weeks.

\section{Flow cytometry}

AT and liver tissues were digested and bone marrow (BM) was flushed from the femur and tibia. Single cell suspensions were stained with a cocktail of antibodies (see online supplementary table 1 and supplementary figures 1 and 2).

\section{RNA isolation, CDNA synthesis and qRT-PCR}

RNA was isolated from murine vAT and liver for cDNA synthesis followed by quantitative PCR. Primer sequences are given in online supplementary table 2 .

\section{Histology}

Frozen murine liver sections were stained with either oil red $\mathrm{O}$ or with antibodies against macrophages (F4/80), T cells (CD3), monocytes/neutrophils (CD11b) and neutrophils (NIMP) as previously described. ${ }^{13} 15$ Paraffin-embedded vAT and liver sections were stained for H\&E or Sirius red to assess hepatic steatosis and fibrosis.

\section{Liver and plasma cholesterol and triglyceride measurements}

Cholesterol and triglycerides were measured in liver homogenates and plasma as described previously. ${ }^{16}$

\section{Cytokine levels}

AT homogenates of donor AT were used to measure cytokine levels of MCP1, interleukin (IL)-6, chemokine (C-X-C motif) ligand1 (CXCL1), interferon-gamma (IFN- $\gamma$ ), IL-1 $\beta$, IL-2, IL-4, IL-5, IL-10, IL-12P70 and tumour necrosis factor (TNF) according to the manufacturer's instructions.

\section{AT culturing}

vAT explants from the three donor groups were cultured. Lipopolysaccharide-induced CXCL14 and CXCL16 secretion were measured using ELISA, following manufacturer's instructions.

\section{CD11 ${ }^{-}$and $\mathrm{CD} 11 \mathrm{c}^{+}$cell sorting and array}

By using fluorescence-activated cell sorting (FACS), CD11 $\mathrm{c}^{+}$and CD11 ${ }^{-}$ATMs were isolated from mice fed either LFD or HFD for 12 weeks for microarray analysis. Data are presented as fold change (FC) in expression level compared with LFD-fed mice. 
Genes showing FCs of at least 1.50 and a p value of less than 0.05 were considered differentially regulated.

\section{Human vAT and liver gene expression data}

vAT and liver microarray data were obtained from vAT and liver biopsies which were taken from 74 patients who are morbidly obese (body mass index 35-70) (see online supplementary table $3)$. Correlations were tested by calculating Pearson's correlation coefficient using SPSS statistics V.23 (IBM). After Bonferroni correction to adjust for multiple testing, $p$ values of $\leq 0.004$ were deemed statistically significant. The population was divided into non-NASH (score of $\leq 4$ ) and NASH (a score of $\geq 5$ ) based on the NAFLD activity score (NAS).

\section{RESULTS}

CD11 $\mathrm{c}^{+}$macrophages accumulate in vAT and correlate with hepatic macrophage content

Before transplanting vAT to lean acceptor mice, we examined the effect of HFD feeding and clodronate-mediated macrophage depletion on AT phenotype in non-transplanted mice. Compared with LFD-fed mice, 16 weeks of HFD feeding

A

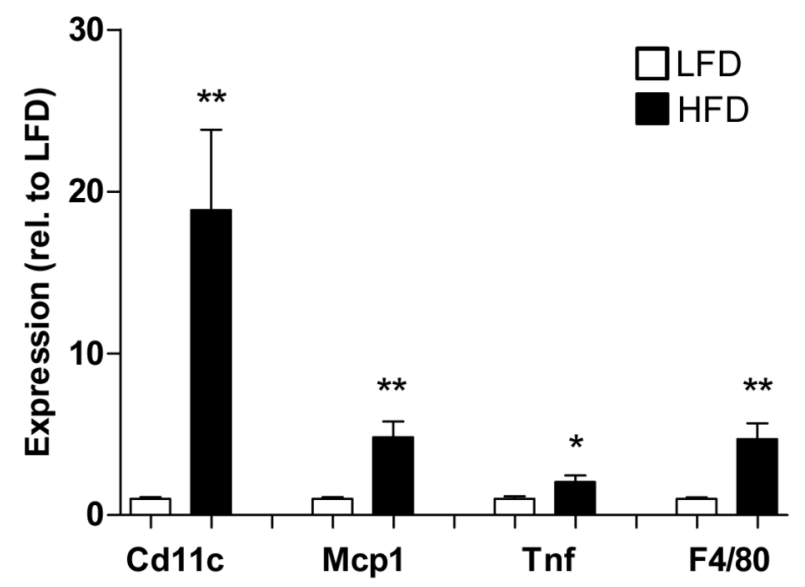

C

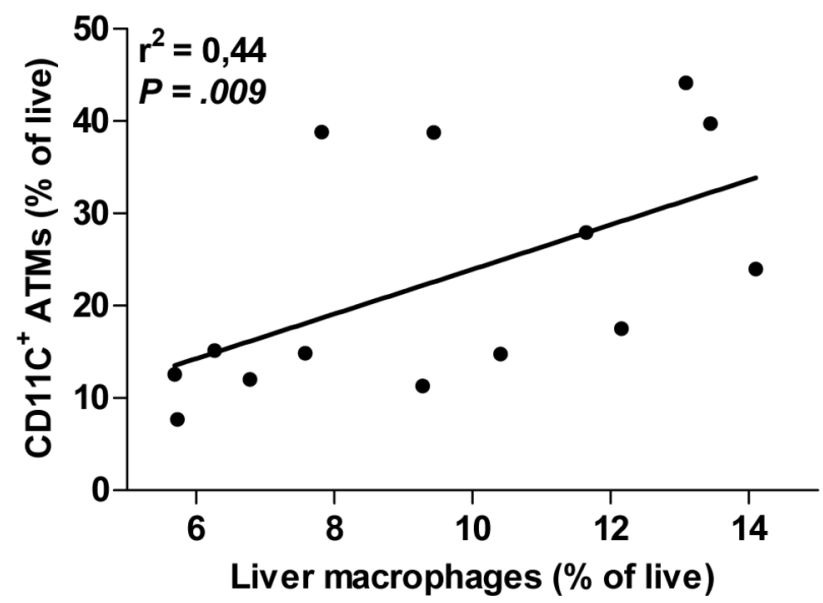

increased body weight over $80 \%$ and vAT and subcutaneous AT (scAT) weights (see online supplementary figure 3A,B). Total immune cell levels were elevated in vAT but not scAT (see online supplementary figure 3C). HFD induced expression levels of Cd11c, Mcp1 (proinflammatory chemokine), Tnf (proinflammatory cytokine) and F4/80 (general macrophage marker) suggesting CD $11 \mathrm{c}^{+}$macrophage accumulation (figure 1A). Flow cytometry analysis revealed a large increase in $\mathrm{CD} 11 \mathrm{c}^{+}$macrophages while CD $11 \mathrm{c}^{-}$macrophages were increased to a lesser extent. Levels of $\mathrm{CD}^{+} \mathrm{T}$ cells were decreased in vAT by HFD feeding while other immune cells were unaffected (figure 1B). Interestingly, liver macrophage content correlated significantly with $\mathrm{CD} 11 \mathrm{c}^{+}$macrophages in vAT but not with CD11 $\mathrm{c}^{-}$ATMs (figure 1C). Liver macrophages did not correlate with dendritic cells (DC), CD8 ${ }^{+}$ $\mathrm{T}$ cells, B cells or granulocytes, but did show a negative correlation with $\mathrm{CD}^{+}{ }^{+} \mathrm{T}$ cells and natural killer cells in vAT (see online supplementary figure $3 \mathrm{D}$ ). These results suggest that $\mathrm{CD} 11 \mathrm{c}^{+}$ATM numbers are linked to liver macrophage content.
B
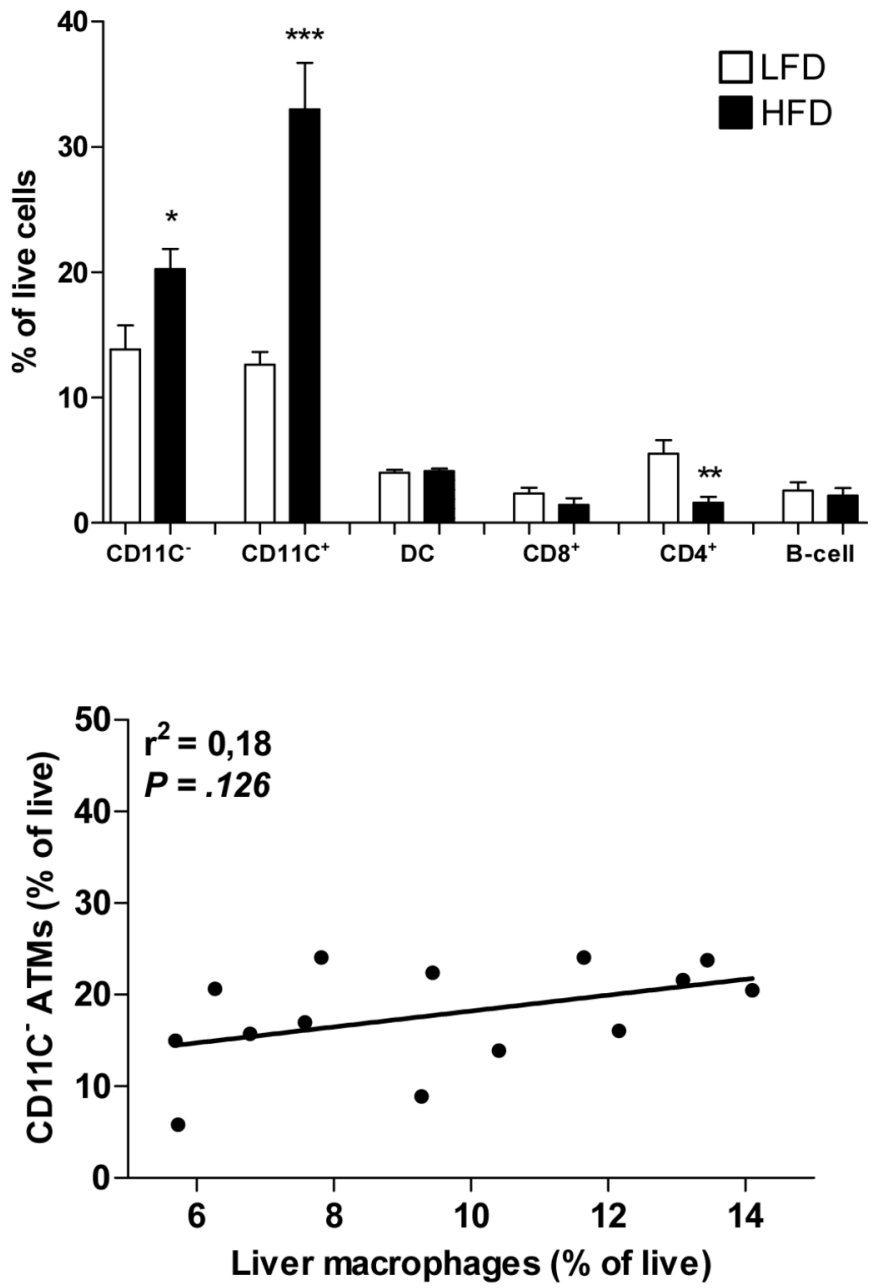

Figure 1 Diet-induced obesity induces accumulation of $\mathrm{CD} 11 \mathrm{c}^{+}$macrophages in visceral adipose tissue which correlates with hepatic macrophages. (A) Gene expression levels of Cd11c, Mcp1, Tnf and F4/80 in visceral adipose tissue (vAT) of mice fed LFD or HFD for 16 weeks. (B) CD11 ${ }^{-}$and CD11 $\mathrm{c}^{+}$macrophages, dendritic cells (DC), CD8 ${ }^{+} \mathrm{T}$ cells, $\mathrm{CD} 4^{+} \mathrm{T}$ cells and B cells were determined by flow cytometry and are displayed as percentage of live cells in vAT of LFD and HFD-fed mice. (C) Correlations of CD11 $\mathrm{c}^{+}$or CD11 $\mathrm{c}^{-}$ATMs with liver macrophages measured with flow cytometry. All data are means $\pm S E M ; n=7$ per group. ${ }^{*} p<0.05,{ }^{* *} p<0.01,{ }^{* * *} p<0.001$ versus LFD. Spearman's rank correlations based on $n=14$. ATM, adipose tissue macrophage; HFD, high-fat diet; LFD, low-fat diet. 

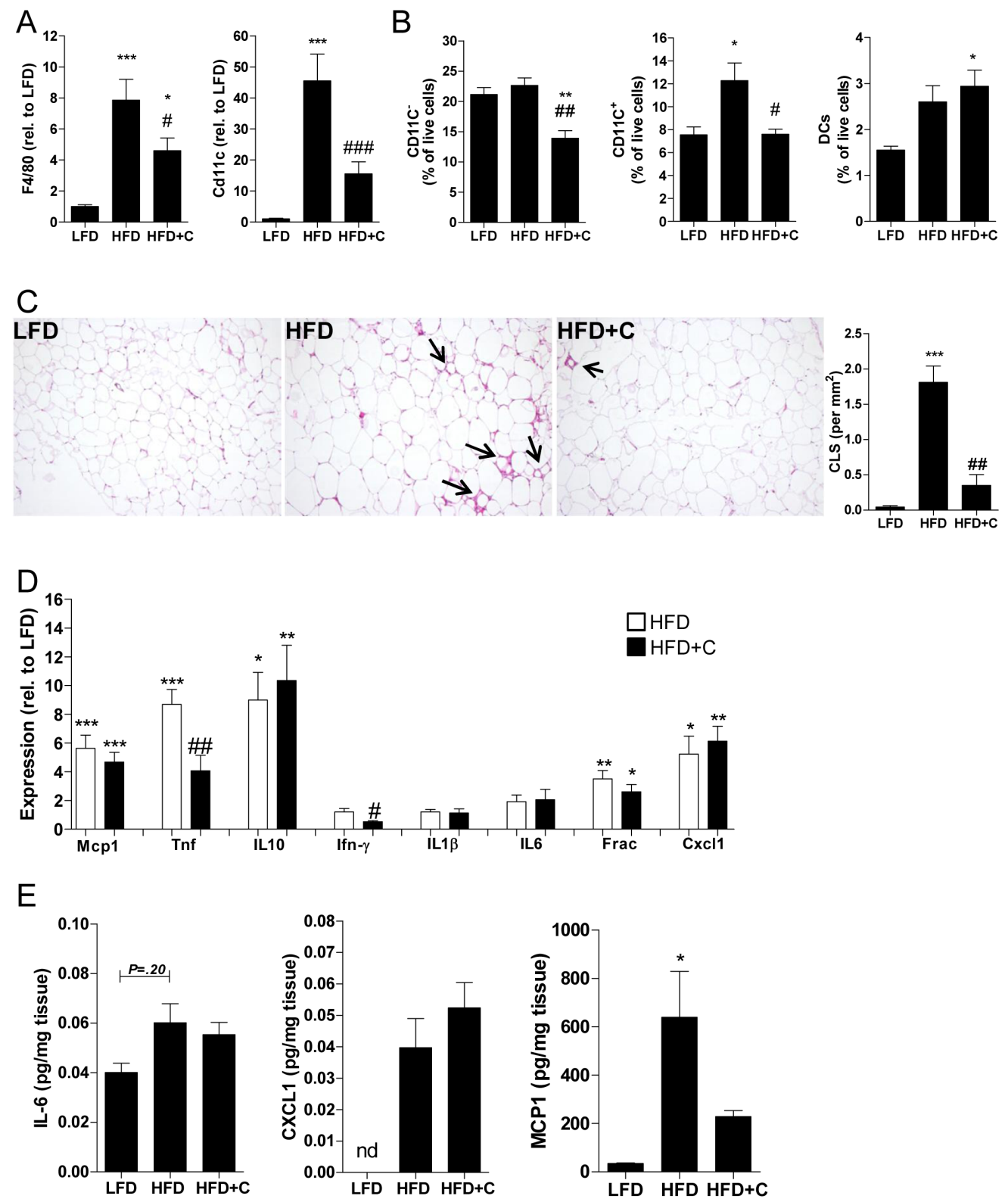

Figure 2 Clodronate liposomes deplete adipose tissue macrophages (ATM) from obese visceral adipose tissue (vAT). (A, B) Gene expression levels of $F 4 / 80$ and $C d 11 C(A)$ and $C D 11 c^{-}$and $C D 11 c^{+}$macrophages and DC numbers displayed as percentage of live cells determined by flow cytometry (B) in vAT of mice fed LFD, HFD or HFD and injected with clodronate liposomes 48 hours before sacrifice (HFD+C). (C) Representative pictures of the vAT stained with H\&E (100x magnification), arrows show crown-like structures (CLSs) and quantification of these structures. (D, E) Gene expression (D) and protein levels (E) of inflammatory markers in the vAT. All data are means \pm SEM; Panel $A, D: n=13-14$ per group. Panel $B, C, E: n=4-6$ per group. ${ }^{*} p<0.05,{ }^{* *} p<0.01,{ }^{* * *} p<0.001$ versus LFD. $\# p<0.05, \# \# p<0.01, \# \#$ $<0.001$ versus HFD. CLS, crown-like structure; DC, dendritic cell; HFD, high-fat diet; HFD+C, HFD and injected with clodronate liposomes; IL, interleukin; LFD, low-fat diet; nd, not detectable.

Clodronate liposomes deplete ATMs from vAT of obese mice Clodronate liposomes blunted the induction of F4/80 and Cd11c expression by HFD feeding (figure 2A). Additionally, clodronate liposomes reduced levels of $\mathrm{CD} 11 \mathrm{c}^{-}$macrophages and normalised levels of $\mathrm{CD} 11 \mathrm{c}^{+}$macrophages in obese mice to levels observed in LFD-fed mice without affecting CD11 ${ }^{+}$ DCs (figure 2B). In agreement, crown-like structures, containing CD $11 \mathrm{c}^{+}$cells, ${ }^{17}$ were nearly absent after clodronate liposome injection (figure 2C). ATM depletion resulted in a decrease in Tnf and Ifn- $\gamma$ (macrophage activating cytokine) gene expression, without affecting expression levels of other cytokines such as IL10 (anti-inflammatory cytokine), IL1 $\beta$ (mediator inflammatory response), IL6 (proinflammatory cytokine), Fractalkine (chemokine and leucocyte adhesion) and Cxcl1 (chemotaxis) (figure 2D). In line, ATM depletion did not affect vAT IL6 and CXCL1 protein levels, while MCP1 protein levels were reduced (figure 2E). Two days after clodronate injection, circulating monocyte levels were normalised, suggesting that that all injected clodronate liposomes were phagocytosed already one day after injection (see online supplementary figure 4A).

\section{ATMs induce hepatic macrophage accumulation in NASH}

All acceptor $1 \mathrm{dlr}^{-1-}$ mice received an HCD to induce NASH for 4 weeks before and 8 weeks after transplantation of donor vAT generating the following groups: LTA, OTA and DOTA. Body 
weight development in response to the HCD and surgery was comparable between the experimental groups, indicating equal recovery (see online supplementary figure 5A). Transplanted AT was examined at the end of the experiment. Transplanted AT was well vascularised via the peritoneum in each mouse (data not shown). In addition, transplanted AT weight (see online supplementary figure 4B), morphology and necrosis (data not shown) were similar between groups. Moreover, F4/80 and CD11c expression levels of transplanted AT were not significantly different between groups 2 or 8 weeks after transplantation (see online supplementary figure 4C,D). Experiments were performed using CD45.1 donor and CD45.2 acceptor mice. These isoforms of CD45 allowed us to distinguish donor and host cells, but do not differ in functionality. CD $45.1^{+}$donor cells were absent in the circulation (see online supplementary figure 5B), liver, spleen, AT and draining lymph nodes of CD45.2 acceptor mice post-transplantation (data not shown), excluding effects of direct migration of donor cells into host tissue. Due to the HCD, circulating monocyte and neutrophil levels were elevated before vAT transplantation $(\mathrm{t}=0) .{ }^{18}{ }^{19}$ vAT transplantation did not further affect blood monocytes in LTA mice. Interestingly, blood monocytes were decreased in OTA mice, while this effect was not observed in DOTA mice (see online supplementary figure 5C). A similar trend was seen for both Ly6c ${ }^{-}$(patrolling) and Ly6c (inflammatory) monocyte subsets (data not shown). Circulating neutrophil levels were unchanged 8 weeks after AT transplantation (see online supplementary figure 5C).

Next, we investigated whether NASH development was affected in OTA or DOTA mice. Liver triglycerides and cholesterol measurements as well as $\mathrm{H} \& \mathrm{E}$ and oil red $\mathrm{O}$ stained liver sections showed equal steatosis between the groups (figure 3A,C, see online supplementary figure 5D,E). Hepatic neutrophil and $\mathrm{T}$ cell numbers did not differ between the groups (figure $3 \mathrm{~B}$ ). Strikingly, hepatic macrophage content was increased in the OTA mice compared with LTA mice while this was not observed in the DOTA mice (figure 3D). In line, hepatic F4/80 expression was lower in DOTA mice compared with OTA mice. Other inflammatory genes, such as Mcp1, Tnf, Mpo (Myeloperoxidase; neutrophil activation marker), Cd11b (myeloid marker present on neutrophils, monocytes and macrophages), and Ly6c (proinflammatory monocyte marker) and Col1a1 (fibrosis marker), were not different between the groups (figure 3E). Staining with Sirius red to visualise fibrosis revealed mild fibrosis which did not differ between the groups (data not shown). Compared with LTA mice, circulating alanine aminotransferase (ALAT) levels were strongly increased in OTA mice, but not in DOTA mice (figure 3F). Plasma glucose and insulin levels did not differ between groups suggesting no effects on insulin resistance (data not shown). These findings indicate that ATMs induce hepatic macrophage accumulation in NASH contributing to hepatic damage.

\section{ATMs rapidly induce the recruitment of hepatic neutrophils}

To investigate the mechanisms responsible for increased hepatic macrophage accumulation in OTA mice, we studied the initiating events by performing a short-term study. Again, vAT transplantation was performed to generate LTA, OTA or DOTA mice which were maintained on a chow diet. Compared with OTA mice, hepatic expression of the neutrophil marker MPO and of the myeloid marker $C d 11 b$ was decreased in DOTA mice suggesting decreased hepatic neutrophil infiltration. S100A8 (involved in neutrophil recruitment) expression levels tended to be decreased in DOTA mice. No difference was observed in inflammation and macrophage-related markers such as $F 4 / 80$, $M c p 1$, Tnf and Ly6c (figure 4A). Flow cytometry data showed a clear accumulation of hepatic neutrophils in OTA mice compared with LTA mice and confirmed the reduction of hepatic neutrophils in DOTA mice (figure 4B). Immunohistochemistry showed a similar but non-significant trend in hepatic neutrophil count (figure 4C,D) while CD11 $\mathrm{b}^{+}$cells were increased in OTA mice but not in DOTA mice (figure 4E). At this time point, there was no difference in $\mathrm{F} 4 / 80^{+}$tissue macrophages (figure $4 \mathrm{~F}$ ). In line, there were no differences in either plasma ALAT (figure 4G) or lipid levels, or in hepatic lipid levels (see online supplementary figure $6 \mathrm{~A}, \mathrm{~B})$. To assess whether lipolysis was affected in donor vAT, gene expression of lipolysis genes (hormone sensitive lipaseand lipoprotein lipase) in the transplanted AT as well as circulating free fatty acids were measured. No differences were found between groups (data not shown). Compared with LTA mice, OTA mice displayed elevated circulating neutrophils after vAT transplantation whereas in DOTA mice circulating neutrophils decreased (figure 5A). Circulating monocytes showed a trend towards increased levels in LTA and OTA but not in DOTA mice (figure 5A). These results suggest that ATMs stimulate neutrophil recruitment, possibly from bone marrow (BM). Therefore, using flow cytometry, we determined levels of BM progenitor cells. Common myeloid progenitor (CMP) cells were higher in OTA and DOTA mice, although not statistically significant. Granulocyte-macrophage progenitor cells, which are derived from CMPs and are neutrophil precursors, ${ }^{20}$ were lower in the DOTA mice compared with the OTA mice (figure $5 \mathrm{~B}$ ), suggesting that ATMs from obese vAT stimulate neutrophil development in BM.

To determine the mechanism by which ATMs induce neutrophil recruitment, we sorted $\mathrm{CD} 11 \mathrm{c}^{+}$and $\mathrm{CD} 11 \mathrm{c}^{-}$macrophages from vAT derived from LFD and HFD-fed mice (similar to donor mice). Microarray analysis was performed to investigate qualitative differences in ATMs induced by obesity. Interestingly, several genes involved in neutrophil chemotaxis, such as members of the CXCL and colony stimulating factor (CSF) families, were specifically upregulated only in $\mathrm{CD} 11 \mathrm{c}^{+} \mathrm{ATMs}$ in response to high fat feeding (figure 5C): Cxcl14 (FC=2.47), Cxcl16 $(\mathrm{FC}=2.01)$ and $\mathrm{Gm}-\mathrm{csf}(\mathrm{FC}=1.67)$. Cxcl1 was increased significantly in both $\mathrm{CD} 11 \mathrm{c}^{+}(\mathrm{FC}=1.84)$ and $\mathrm{CD} 11 \mathrm{c}^{-}(\mathrm{FC}=2.14)$ cells after HFD feeding. In total vAT, HFD feeding increased gene expression of CXCL14 and CXCL16. Depletion of ATMs using clodronate reduced both CXCL14 and CXCL16 expression, but this reduction was only significant for CXCL14 (see online supplementary figure 7A). Taken together, these data show that, in addition to their accumulation in vAT during obesity, $\mathrm{CD} 11 \mathrm{c}^{+}$cells feature enhanced expression of neutrophil chemoattractants. Finally, culturing vAT from the three different types of donor mice showed that CXCL14 and CXCL16 protein secretion is induced in vAT from obese mice and ATM depletion normalised this secretion to the levels observed in vAT from lean animals (figure 5D). These results suggest that ATMs are responsible for the secretion of neutrophil chemoattractants by vAT.

\section{Human CD11c expression in vAT correlates with liver neutrophil and macrophage markers}

To investigate if our findings were translatable to human liver disease, we analysed hepatic and vAT transcriptomic data of bariatric surgery patients (see online supplementary table 3). Based on the NAFLD activity score (NAS), subjects were divided into non-NASH $(\mathrm{NAS} \leq 4)$ patients and patients with $\mathrm{NASH}$ (NAS $\geq 5$ ). Although all patients displayed morbid obesity, gene 
A

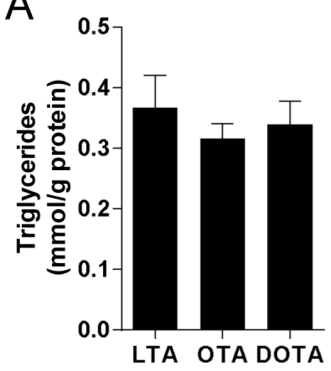

C

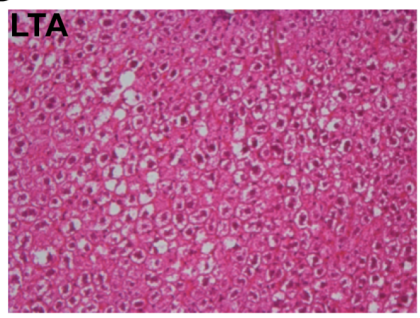

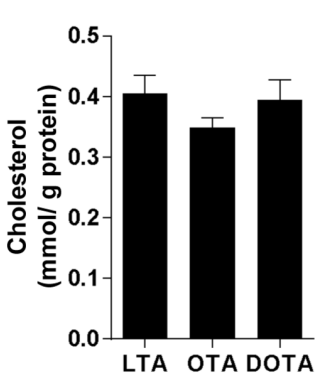

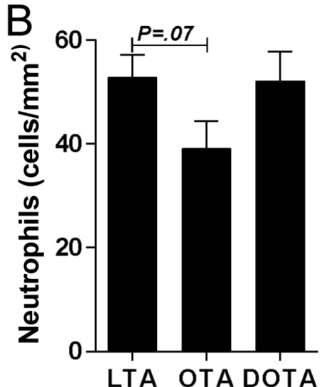

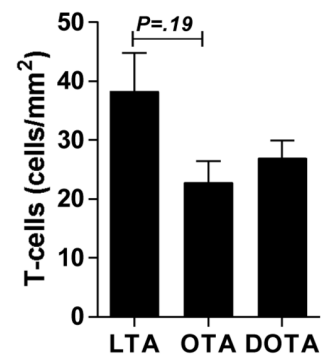
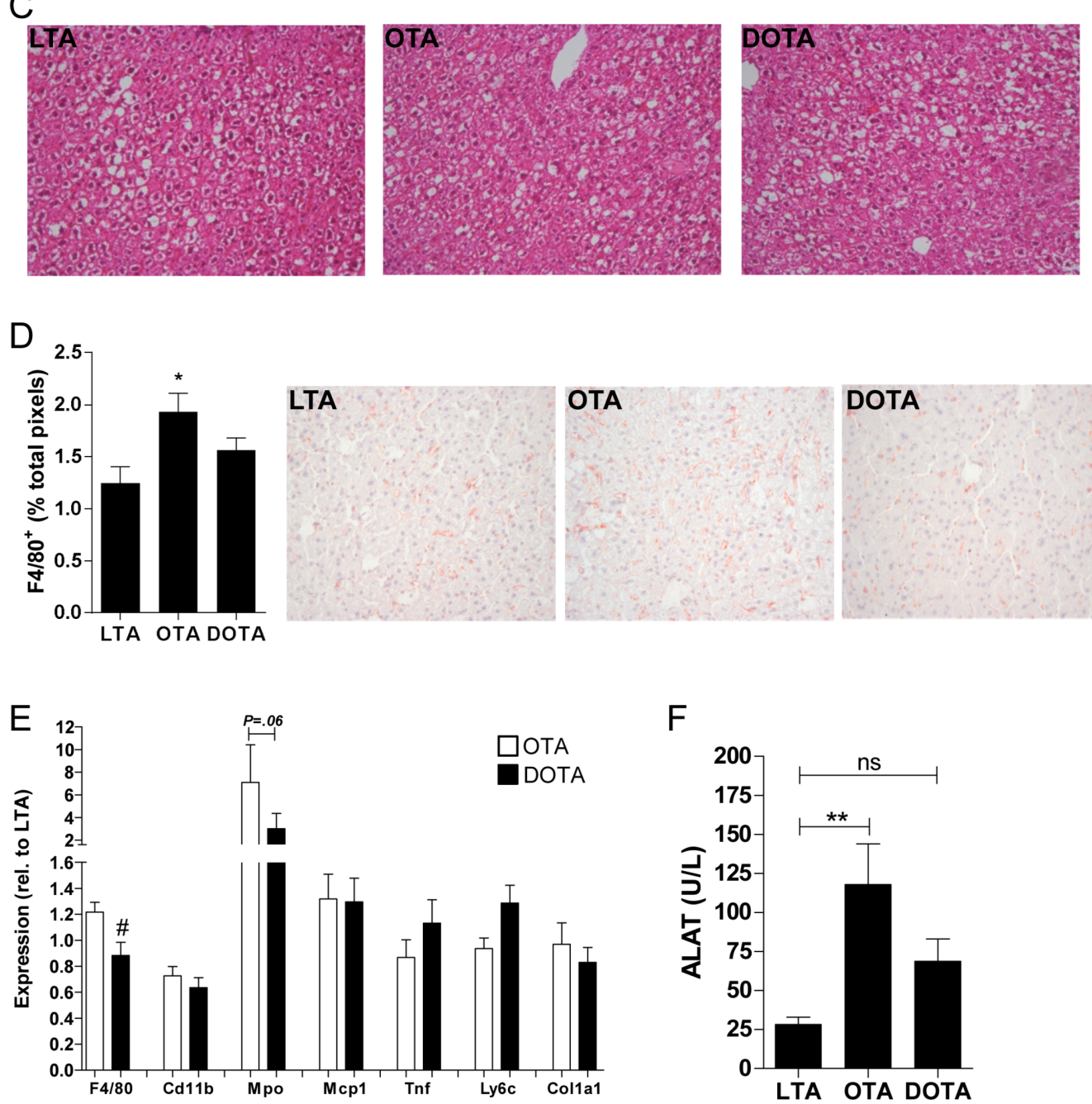

Figure 3 Adipose tissue macrophages induce hepatic macrophage accumulation in non-alcoholic steatohepatitis (NASH). (A, C) Liver triglyceride and cholesterol levels (A) including representative photos (200x magnification) of the H\&E stained liver sections (C) of LTA, OTA and DOTA mice fed a high-cholesterol diet (HCD) for a total of 12 weeks. (B) Quantification of immunohistochemical staining of hepatic neutrophil and T cell numbers in the LTA, OTA and DOTA mice. (D) Representative photos of the LTA, OTA and DOTA mice livers stained for F4/80 (200x magnification) and the corresponding quantification. (E) Hepatic gene expression levels of inflammatory, immune cell-specific and fibrotic markers. (F) Circulating ALAT levels. All data are means \pm SEM; $n=9-12$ per group. ${ }^{*} p<0.05$ versus LTA. ${ }^{*} p<0.05$ versus LTA. \#p $<0.05$ versus OTA. ALAT, alanine aminotransferase; DOTA, ATM-depleted obese-transplanted acceptors; LTA, lean-transplanted acceptors; ns, not significant; OTA, obese-transplanted acceptors.

expression of CXCL5, CXCL16 and M-CSF was only increased in patients who are obese with NASH. Other inflammatory genes, including $C D 11 c$, tended to be higher in patients who are obese with NASH (see online supplementary table 4). Next, we investigated whether macrophage markers in vAT correlated with macrophage and neutrophil markers in the livers of the same individuals (table 1). CD11c gene expression was used as a marker of CD11 $\mathrm{c}^{+}$ATMs, while for CD11 ${ }^{-}$ATMs, we analysed MRC1, a known marker of alternatively activated resident $\mathrm{CD}_{11 \mathrm{c}^{-}}$AT macrophages. ${ }^{10} \mathrm{CD} 11 \mathrm{c}$ expression in vAT correlated with hepatic expression of the neutrophil markers MPO $(\mathrm{R}=0.331 ; \mathrm{p}=0.004)$ and CD15 $(\mathrm{R}=0.328 ; \mathrm{p}=0.004) .{ }^{21} 22$ We did not find a correlation between MRC1 in vAT and hepatic MPO, CD15 or CD11b expression. CD11c in vAT did not correlate with hepatic FCGR2A $(\mathrm{R}=0.246 ; \mathrm{p}=0.035)$, a general macrophage marker, or with MRC1 $(\mathrm{R}=0.061 ; \mathrm{p}=0.608)$, but did show a strong correlation with hepatic $C D 11 c$ expression $(\mathrm{R}=0.426 ; \mathrm{p}=0.000)$. vAT MRC1 did not correlate with any of these markers in the liver.

Next, we studied the association of CD11c or MRC1 in vAT with neutrophil chemotaxis genes in vAT. Strong correlations 
A

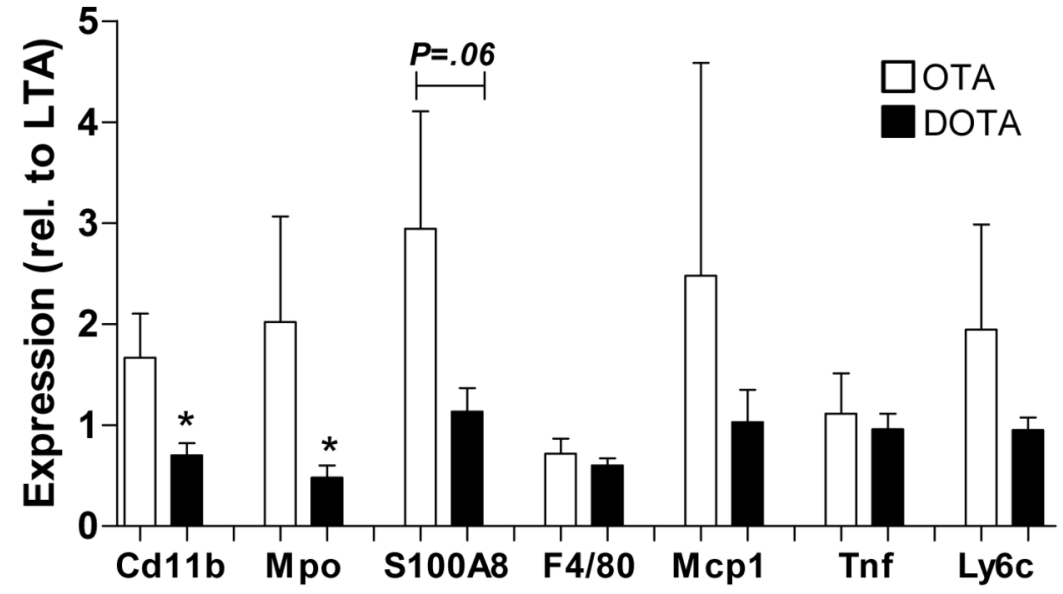

B

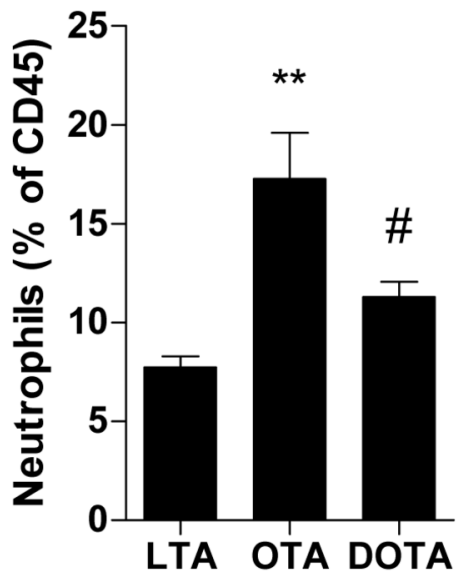

C
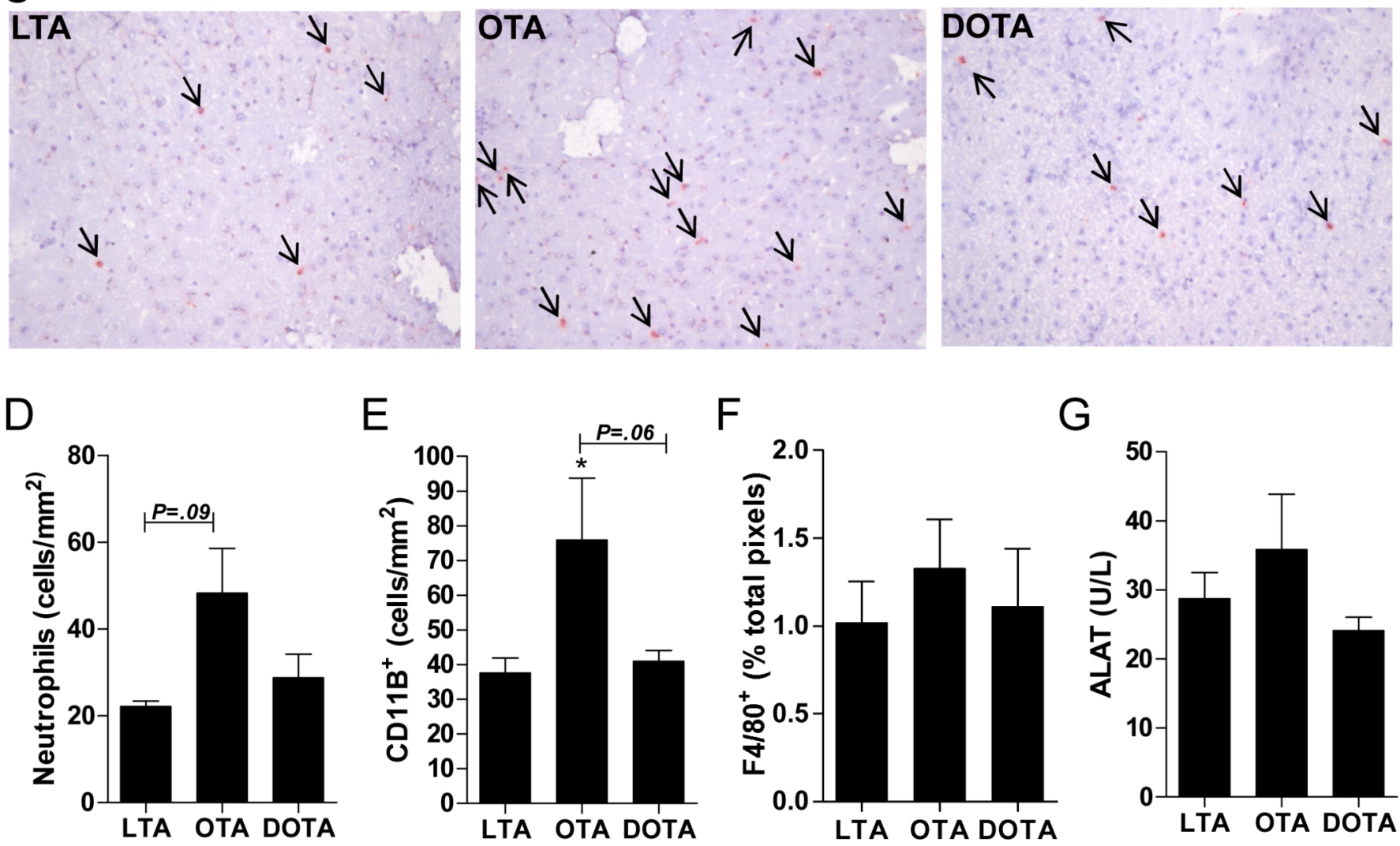

Figure 4 Hepatic neutrophil infiltration is triggered by adipose tissue macrophages. (A, B) Hepatic gene expression levels of inflammatory markers (A) and liver neutrophil levels measured by fluorescence-activated cell sorting (FACS) (B) in LTA, OTA and DOTA mice 2 weeks after transplantation and fed a standard chow diet. (C, D) Representative pictures of hepatic neutrophil staining (200x magnification, arrows show positive cells) (C) and corresponding quantification (D). (E, F) Quantification of CD11b positive cells (E) and F4/80 staining (F) in the liver. (G) Plasma ALAT levels. All data are means $\pm S E M ; n=4-5$ per group. ${ }^{*} p<0.05,{ }^{*} p<0.01$ versus LTA. \#p $<0.05$ versus OTA. ALAT, alanine aminotransferase; DOTA, ATM-depleted obesetransplanted acceptors; LTA, lean-transplanted acceptors; OTA, obese-transplanted acceptors.

were found between CD11c and CXCL2 $(\mathrm{R}=0.695 ; \mathrm{p}=0.000)$, CXCL5 ( $\mathrm{R}=0.565 ; \mathrm{p}=0.000)$, CXCL8 (human homologue of murine CXCL1; $\mathrm{R}=0.736 ; \mathrm{p}=0.000)$, CXCL16 $(\mathrm{R}=0.504$; $\mathrm{p}=0.000), \quad S 100 A 8 \quad(\mathrm{R}=0.813 ; \mathrm{p}=0.000) \quad$ and $\quad G-C S F$ $(\mathrm{R}=0.702 ; \mathrm{p}=0.000)$, but not with GM-CSF $(\mathrm{R}=-0.016$; $\mathrm{p}=0.895)$ or $M-C S F(\mathrm{R}=0.069 ; \mathrm{p}=0.559)$. Conversely, MRC1 did not correlate with any of the chemotaxis markers (table 2). Although numerically outnumbered by ATMs, DCs also express CD11c. vAT expression of the DC marker gene FLT3 did not correlate with any of the investigated genes in the liver and only correlated with CXCL5 $(R=0.355 ; \mathrm{p}=0.002)$ in the vAT (see online supplementary tables 5 and 6 ), arguing against DC involvement. ${ }^{23}$ Taken together, these findings are in line with our data showing that CD $11 \mathrm{c}^{+}$macrophages in vAT mediate the increased neutrophil chemotaxis and hepatic inflammation. 
A
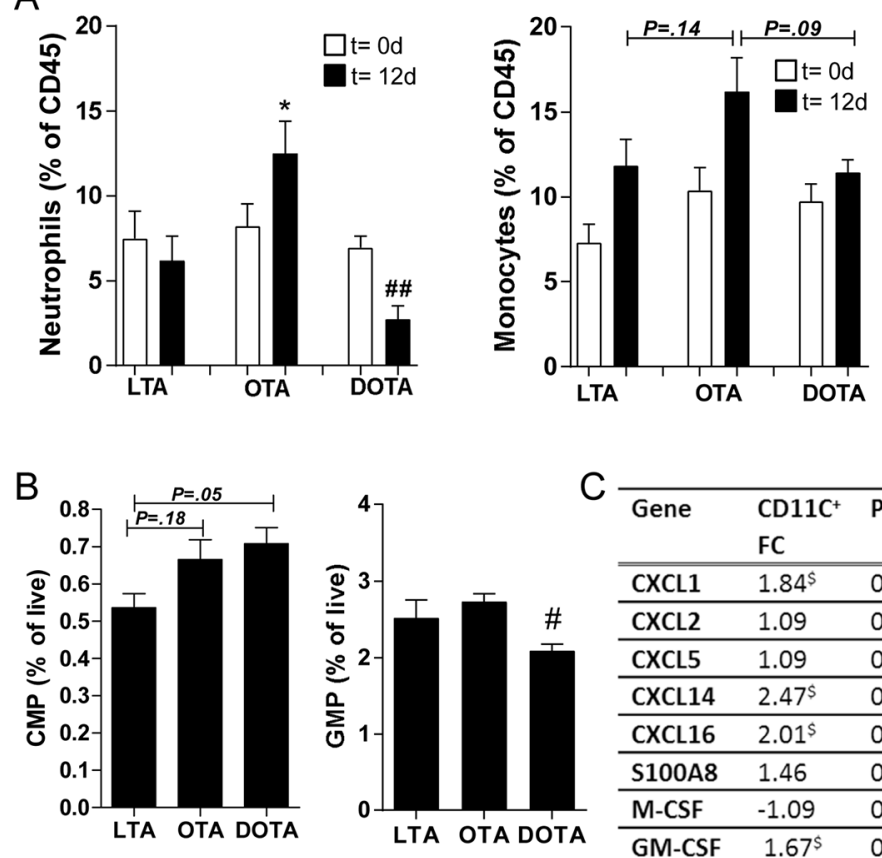

\begin{tabular}{|c|c|c|c|c|}
\hline Gene & $\begin{array}{l}\text { CD11C }^{+} \\
\text {FC }\end{array}$ & P-value & $\begin{array}{l}\text { CD11C- } \\
\text { FC }\end{array}$ & P-value \\
\hline CXCL1 & $1.84^{\mathrm{S}}$ & 0.002 & $2.14^{\mathrm{s}}$ & 0.000 \\
\hline CXCL2 & 1.09 & 0.445 & 1.37 & 0.010 \\
\hline CXCL5 & 1.09 & 0.592 & 1.29 & 0.141 \\
\hline CXCL14 & $2.47^{5}$ & 0.000 & 1.17 & 0.343 \\
\hline CXCL16 & $2.01^{s}$ & 0.000 & 1.49 & 0.015 \\
\hline S100A8 & 1.46 & 0.473 & 1.03 & 0.948 \\
\hline M-CSF & -1.09 & 0.637 & -1.28 & 0.207 \\
\hline GM-CSF & $1.67^{\mathrm{s}}$ & 0.021 & -1.02 & 0.931 \\
\hline G-CSF & $-1.63^{s}$ & 0.013 & -1.15 & 0.429 \\
\hline
\end{tabular}
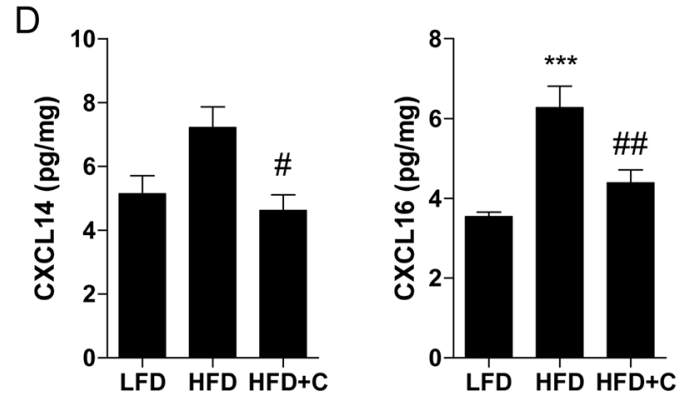

Figure 5 CD11 $\mathrm{C}^{+}$adipose tissue macrophages (ATM) increase circulating neutrophils and their recruitment from the bone marrow. (A) Circulating neutrophils and monocytes before and 12 days after AT transplantation in LTA, OTA and DOTA mice on a chow diet. (B) Bone marrow fluorescenceactivated cell sorting (FACS) data displaying CMP and GMP cells as percentage of live bone marrow cells 2 weeks after transplantation. (C) Fold changes (FC) in gene expression of a cluster of genes involved in neutrophil chemotaxis in CD11 ${ }^{+}$and $C D 11 c^{-}$macrophages after HFD feeding. All data are means $\pm S E M ; n=4-5$ per group. ${ }^{*} p<0.05$ versus LTA. \#p $<0.05$, \#\#p<0.01 versus OTA. ${ }^{5} F C \geq 1.50$ and $p<0.05$ was considered differentially regulated. (D) CXCL14 and CXCL16 protein levels measured in medium after culturing adipose tissue derived from donor mice expressed as pg produced per $\mathrm{mg}$ AT. $\mathrm{n}=4-6$. Representative data shown of experiment, which was performed three times. All data are means $\pm \mathrm{SEM}$; ${ }^{* * *} \mathrm{p}<0.001$ versus LFD. \#p $<0.05$, \#\#p $<0.01$ versus HFD. CMP, common myeloid progenitor cells; DOTA, ATM-depleted obese-transplanted acceptors; GMP, granulocyte-macrophage progenitor cells; HFD, high-fat diet; HFD+C, HFD and injected with clodronate liposomes; LFD, low-fat diet; LTA, leantransplanted acceptors; OTA, obese-transplanted acceptors.

\section{DISCUSSION}

Our study shows that transplantation of AT from obese mice rapidly causes elevated circulating neutrophils and hepatic neutrophil infiltration. Increased expression of genes involved in neutrophil recruitment, in $\mathrm{CD} 11 \mathrm{c}^{+} \mathrm{ATMs}$, probably contributes to hepatic neutrophil accumulation. Furthermore, in an experimental model of NASH, transplanting CD11 $\mathrm{c}^{+}$
ATM-rich AT of obese mice resulted in more hepatic macrophage accumulation and enhanced liver damage. Depleting ATMs from obese donor AT prior to transplantation inhibited the effects on neutrophil and macrophage accumulation, indicating that $\mathrm{CD} 11 \mathrm{c}^{+} \mathrm{ATMs}$ directly contribute to hepatic inflammation. Lastly, CD11c expression was associated with neutrophil chemotaxis gene expression in human AT biopsies.

Table 1 Correlations of CD11c and MRC1 expression in human vAT with neutrophil and macrophage markers in the liver

\begin{tabular}{llcccccc}
\hline & & MPO (liver) & CD15 (liver) & CD11b (liver) & FCGR2A (liver) & CD11c (liver) & MRC1 (liver) \\
\hline \multirow{2}{*}{ CD11c (vAT) } & R value & $0.331^{*}$ & $0.328^{*}$ & 0.160 & 0.246 & $0.426^{*}$ & 0.061 \\
& p Value & 0.004 & 0.004 & 0.173 & 0.035 & 0.000 & 0.608 \\
\multirow{2}{*}{ MRC1 (vAT) } & R value & -0.185 & 0.001 & -0.023 & -0.016 & 0.057 & 0.025 \\
& p Value & 0.114 & 0.993 & 0.845 & 0.890 & 0.629 & 0.832 \\
\hline
\end{tabular}

$\mathrm{R}$ values and corresponding $\mathrm{p}$ values of the Pearson's correlations between $C D 11 \mathrm{c}$ and $M R C 1$ in vAT with $M P O, C D 15, C D 11 \mathrm{~b}, F C G R 2 A, C D 11 \mathrm{c}$ and $M R C 1$ in liver. $\mathrm{n}=74$.

${ }^{*} p \leq 0.004$ was deemed statistically significant due to adjustment for multiple testing.

vAT, visceral adipose tissue. 
Table 2 Correlations of CD11C and MRC1 expression with neutrophil chemotaxis genes in human vAT

\begin{tabular}{llcccccccc}
\hline & & CXCL2 (vAT) & CXCL5 (vAT) & CXCL8 (vAT) & CXCL16 (vAT) & S100A8 (vAT) & G-CSF (vAT) & GM-CSF(vAT) & M-CSF (vAT) \\
\hline CD11c (vAT) & R value & $0.695^{*}$ & $0.565^{*}$ & $0.736^{*}$ & $0.504^{*}$ & $0.813^{*}$ & $0.702^{*}$ & -0.016 & 0.069 \\
& $p$ Value & 0.000 & 0.000 & 0.000 & 0.000 & 0.000 & 0.000 & 0.895 & 0.559 \\
\multirow{2}{*}{ MRC1 (vAT) } & R value & 0.048 & -0.032 & 0.046 & 0.024 & 0.008 & 0.092 & 0.030 & 0.045 \\
& $p$ Value & 0.685 & 0.787 & 0.696 & 0.838 & 0.943 & 0.435 & 0.798 & 0.701 \\
\hline
\end{tabular}

$R$ values and corresponding $p$ values of the Pearson's correlations between CD11C and MRC1 with CXCL2, CXCL5, CXCL8, CXCL16, S100A8, G-CSF, GM-CSF and M-CSF in vAT. $\mathrm{n}=74$.

${ }^{*} p \leq 0.004$ was deemed statistically significant due to adjustment for multiple testing. vAT, visceral adipose tissue.

Strikingly, AT CD11c expression also correlated with gene expression of neutrophil and macrophage markers in paired human liver biopsies.

Previously, it has been shown that visceral ATM numbers and liver histopathology (steatosis, fibrosis and inflammation score) are associated in morbidly obese subjects. ${ }^{12}$ Using FACS analysis on murine AT, we now show that specifically CD $11 c^{+}$, but not $\mathrm{CD} 11 \mathrm{c}^{-}$, macrophages are associated with hepatic macrophages. Moreover, our microarray data in human AT and liver biopsies confirm this link between CD11c ${ }^{+}$ATMs and hepatic pathophysiology.

Transplanting AT from obese mice, rich in $\mathrm{CD}_{11 \mathrm{c}^{+}}$macrophages, to non-hypercholesteraemic mice rapidly resulted in elevated circulating and hepatic neutrophil levels, but not when transplanting AT from obese mice from which ATMs were depleted prior to transplantation. A potential role of neutrophils in NASH has been previously suggested as MPO-deficient mice have reduced hepatic inflammation and attenuated NASH development. ${ }^{24}$ However, the increase in hepatic neutrophil accumulation we observed 12 days after AT transplantation did not coincide with macrophage accumulation or elevated liver enzyme levels. Neutrophils are the first cell type to be recruited in response to infections or damage, followed by monocyte recruitment and macrophage accumulation to tissues. ${ }^{25}$ Hence, it is possible that neutrophil recruitment is a primary event leading to further liver inflammation. In line, our data show that during NASH development, AT from obese mice enhanced hepatic macrophage accumulation in acceptor mice and increased circulating liver enzyme levels, suggesting enhanced liver damage. Again, these effects were mediated by obesity-induced ATMs since depletion of ATMs before transplantation did not increase macrophage accumulation or ALAT levels. Collectively, these data suggest a certain sequence of events where ATMs trigger the recruitment of neutrophils via enhanced production of chemokines, leading to their accumulation in the liver. Next, these acute events probably lead to hepatic macrophage accumulation resulting in liver damage. In line, Nagareddy et al previously showed that ATMs can mediate BM production of neutrophils. ${ }^{26}$ Moreover, disrupting inflammatory signalling in CD11c expressing cells decreased circulating neutrophil and neutrophil precursor levels in BM. These data argue in favour of a causal role for CD $11 \mathrm{c}^{+}$macrophages. ${ }^{26}$ By performing microarray analysis on sorted CD $11 \mathrm{c}^{+}$and CD $11 \mathrm{c}^{-}$cells derived from AT of lean and obese mice, we now accurately determined gene expression of chemoattractant proteins in specific macrophage populations instead of in whole AT. Our data showed an increased expression of neutrophil chemotaxis genes in specifically $\mathrm{CD} 11 \mathrm{c}^{+}$macrophages. Most of the upregulated genes in $\mathrm{CD}_{11 \mathrm{c}^{+}}$macrophages belong to the CXCL chemokine family which are known to primarily attract neutrophils. ${ }^{27}$ In particular, CXCL1/CXCL8 and CXCL16 have been well described to recruit neutrophils in vivo, while CXCL14 is considered a strong chemoattractant of neutrophils based on in vitro assays. ${ }^{25}$ 27-30 Interestingly, du Plessis et al previously described a correlation between CXCL8 and liver inflammation or NAS, further strengthening the importance of this inflammatory protein in liver pathology. ${ }^{11}$ Furthermore, inhibition of CXCL14 was shown to reduce hepatic damage and mortality in a murine hepatotoxicity model. However, hepatic immune cell infiltration was not investigated. ${ }^{31}$ Interestingly, Wehr et al showed that inhibition of CXCL16 reduced macrophage infiltration in an inflammatory model of NASH. ${ }^{32}$ Unfortunately, neutrophil levels were not investigated in this study. In addition to gene expression data in specific ATM subsets, we also showed that AT from obese mice displays increased secretion of CXCL14 and CXCL16, while this secretion was blunted when ATMs were depleted. Thus, our data show that in addition to the increased numbers of $\mathrm{CD} 11 \mathrm{c}^{+}$cells in AT, obesity enhanced production of neutrophil chemotaxis proteins in these cells.

Previous human studies found associations between liver histopathology and ATMs in general, but did not investigate CD $11 c^{+}$and CD $11 c^{-}$cells separately. ${ }^{11} 12$ To discriminate between these macrophage subsets, we used CD11c expression as a marker of CD11 $\mathrm{c}^{+}$macrophages (M1) and MRC1 expression as a marker of CD11 ${ }^{-}$macrophages (M2). Our data show that AT expression of CD11c, but not of MCR1, correlated with neutrophil and macrophage markers in the livers of the same subjects. These data indicate that CD $11 \mathrm{c}^{+}$ (M1) and not CD11 ${ }^{-}$(M2) ATMs are associated with liver pathology in humans. This notion is in agreement with findings of du Plessis et al showing that $\mathrm{CD} 11 \mathrm{c}^{+}$cells are more frequent in AT from patients with NASH compared with non-NASH patients and are of vital importance in NAFLD to NASH progression. ${ }^{11}$ Our human data also confirmed the data of sorted cell murine ATMs showing higher expression of neutrophil chemotaxis genes in $\mathrm{CD}_{11 \mathrm{c}^{+}}$macrophages after HFD feeding. The expression of the CXCL chemokine family, which has similar functions regarding neutrophil chemotaxis in humans, correlated strongly with CD11c but not with MRC1 expression in AT. Moreover, the expression of the chemoattractant genes, CXCL5, CXCL16 and M-CSF, was elevated in the AT of patients who are obese with NASH compared with obese subjects without NASH. Our microarray data from human tissues also revealed some other genes that may be relevant to NAFLD in humans. In AT, CXCL2 and CXCL5, both involved in neutrophil recruitment and homeostasis, correlated with CD11c expression. ${ }^{33-35}$ Interestingly, there was also a strong correlation between CD11c and S100A8 in our human AT data, corresponding with data from Nagareddy et al describing higher levels of S100A8 and A9 in AT of obese mice when compared with AT of lean mice. ${ }^{26}$ The S100 protein family has been implicated in neutrophil recruitment and more specifically the S100A8/9-TLR4 axis was shown to be involved in ATM-induced myelopoiesis. ${ }^{26} 3637$ 
Our findings are in agreement with the notion that neutrophil chemotaxis proteins are being expressed by human CD $11 \mathrm{c}^{+}$ ATMs. Together with our experimental results in mice, these results suggest that $\mathrm{CD} 11 \mathrm{c}^{+}$ATMs contribute to neutrophil recruitment to the liver.

In our long-term murine experiment, hepatic macrophage content was increased after transplanting AT from obese mice. However, this was not paralleled by an increase in circulating monocytes or neutrophils after 8 weeks. Remarkably, we even noted a significant decrease in monocytes after transplantation of AT from obese mice which was not seen in the mice transplanted with ATM-depleted AT. Possibly, this decrease in circulating monocytes reflects enhanced hepatic recruitment, followed by their differentiation into tissue macrophages. In addition, since all mice received HCD already before performing AT transplantation, circulating monocyte levels were already high at baseline. This high baseline level of circulating monocytes might explain why we did not observe monocytosis after AT transplantation, in contrast with the findings of Nagareddy et al. ${ }^{26}$ Finally, the effects of the transplanted AT on circulating cells and BM may be primarily acute and therefore might have been no longer present after 8 weeks. ${ }^{18} 19$ This reasoning is strengthened by the fact that we did see increases in monocytes and neutrophils 2 weeks post-transplantation. Differences with the study of Nagareddy et al may be explained by location of the transplanted AT. In our study, AT was transplanted into the peritoneal cavity while Nagareddy et al transplanted AT into the subcutaneous space. ${ }^{26}$ By transplanting AT to the parietal peritoneum, portal venous drainage of the transplanted AT was prevented in our study. Portal drainage of AT grafts has effects on insulin sensitivity, potentially via portal migration of cells or cytokines to the liver. ${ }^{9}$ Indeed, we did not detect any differences between groups in plasma glucose or insulin levels. Therefore, our results point to a systemic effect of the ATMs independent from direct drainage into the portal vein. Unfortunately, our model for NASH, the $1 \mathrm{dll}^{-/-}$mouse fed an HCD, did not allow us to investigate other relevant parameters of NASH. This model is excellent for rapidly inducing steatosis and inflammation, but fibrosis is mild and hepatocyte damage characterised by hepatocyte ballooning is limited. ${ }^{13} 14$

An important limitation in our human study is intrinsic to the statistical method employed which can only show associations and is not able to determine causality. Therefore, we can merely state that a change in CD11c expression in AT is associated with expression changes in macrophage or neutrophil genes in liver or neutrophil chemotaxis genes in AT. Protein levels or FACSsorted individual cell populations were also not obtained from human AT and therefore we were limited to gene expression data, which does not always show a clear relation with protein levels. Therefore, causal relationships can only be assumed based on our murine data. Prospective studies are needed to fully elucidate the contribution of $\mathrm{CD} 11 \mathrm{c}^{+}$macrophages to NASH progression. However, these studies prove to be challenging to perform as they would require multiple AT and liver biopsies. Therefore, we are currently limited to studies such as our own which can only reveal associations.

In conclusion, obesity induces accumulation of $\mathrm{CD} 11 \mathrm{c}^{+}$ macrophages in AT, which produce more neutrophil regulatory and stimulating proteins resulting in elevated circulating neutrophil levels. The resulting hepatic neutrophil infiltration might lead to enhanced macrophage accumulation and contribute to NASH development. As both the CXCL and S100 protein family consists of targetable proteins, further investigation into specific inhibitors is warranted.

\section{Author affiliations}

${ }^{1}$ Department of Internal Medicine, MUMC, Maastricht, Limburg, The Netherlands ${ }^{2}$ Cardiovascular Research Institute Maastricht, MUMC, Maastricht, Limburg, The Netherlands

${ }^{3}$ Department of Medicine, NYU School of Medicine, New York City, New York, USA ${ }^{4}$ Department of Pathology, MUMC, Maastricht, Limburg, The Netherlands

${ }^{5}$ Department of General Surgery, MUMC, Maastricht, Limburg, The Netherlands ${ }^{6}$ Department of General Surgery, Atrium Medical Centre Parkstad, Heerlen, The Netherlands

${ }^{7}$ Department of Pediatrics, Molecular Genetics, UMCG, Groningen, The Netherlands

Correction notice This article has been corrected since it published Online First. A citation for supplementary figures 1 and 2 has been added as well as the files.

Acknowledgements We would like to thank Professor Dr HJ Verkade and OAHO Ronda (University Medical Centre Groningen, The Netherlands) for kindly providing part of the animal diets and MPH van de Waarenburg (Maastricht University Medical Centre, The Netherlands) for performing various measurements.

Contributors MB performed experiments, analysed the data and wrote the manuscript. TJ and IC performed experiments and analysed data. CJM, MV and JvdG performed experiments. EW contributed to flow cytometry experimental design and measurements. SSR collected human tissue samples and analysed human microarray data. JWMG performed bariatric surgery. MHH collected and analysed human microarray data. EALB supervised flow cytometry design and measurements. CDAS and CGS supervised experiments and revised the manuscript. KW designed the study, performed experiments, analysed the data, supervised experiments and wrote the manuscript.

Funding This study was financed by The Netherlands Organization for Scientific Research (NWO) (Veni 916.12.056), The Netherlands Heart Foundation (2013T143) and a Seventh Framework Program (FP7) Grant (CIG 322070) to KW.

Competing interests None declared.

Ethics approval Medical Ethics Board of Maastricht University Medical Centre.

Provenance and peer review Not commissioned; externally peer reviewed.

(c) Article author(s) (or their employer(s) unless otherwise stated in the text of the article) 2018. All rights reserved. No commercial use is permitted unless otherwise expressly granted.

\section{REFERENCES}

1 Nguyen DM, El-Serag HB. The epidemiology of obesity. Gastroentero/ Clin North Am 2010;39:1-7.

2 Wild $\mathrm{SH}$, Byrne CD. ABC of obesity. Risk factors for diabetes and coronary heart disease. BMJ 2006:333:1009-11.

3 Festi D, Colecchia A, Sacco T, et al. Hepatic steatosis in obese patients: clinical aspects and prognostic significance. Obes Rev 2004;5:27-42.

4 Than NN, Newsome PN. A concise review of non-alcoholic fatty liver disease. Atherosclerosis 2015;239:192-202

5 Ekstedt M, Franzén LE, Mathiesen UL, et al. Long-term follow-up of patients with NAFLD and elevated liver enzymes. Hepatology 2006;44:865-73.

6 Tailleux A, Wouters K, Staels B. Roles of PPARs in NAFLD: potential therapeutic targets. Biochim Biophys Acta 2012;1821:809-18.

7 Gaens KH, Niessen PM, Rensen SS, et al. Endogenous formation of $\mathrm{N \varepsilon}$ (carboxymethyl)lysine is increased in fatty livers and induces inflammatory markers in an in vitro model of hepatic steatosis. J Hepatol 2012;56:647-55.

8 Mirza MS. Obesity, Visceral Fat, and NAFLD: Querying the Role of Adipokines in the Progression of Nonalcoholic Fatty Liver Disease. ISRN Gastroenterol 2011;doi:10.5402/2011/592404. [Epub ahead of print 28 Aug 2011].

9 Rytka JM, Wueest S, Schoenle EJ, et al. The portal theory supported by venous drainage-selective fat transplantation. Diabetes 2011:60:56-63.

10 Boutens L, Stienstra R. Adipose tissue macrophages: going off track during obesity. Diabetologia 2016;59:879-94

11 du Plessis J, van Pelt J, Korf H, et al. Association of adipose tissue inflammation with histologic severity of nonalcoholic fatty liver disease. Gastroenterology 2015; 149:635-48.

12 Tordjman J, Poitou C, Hugol D, et al. Association between omental adipose tissue macrophages and liver histopathology in morbid obesity: influence of glycemic status. J Hepatol 2009;51:354-62.

13 Wouters K, van Gorp PJ, Bieghs V, et al. Dietary cholesterol, rather than liver steatosis, leads to hepatic inflammation in hyperlipidemic mouse models of nonalcoholic steatohepatitis. Hepatology 2008:48:474-86.

14 Bieghs V, Van Gorp PJ, Wouters K, et al. LDL receptor knock-out mice are a physiological model particularly vulnerable to study the onset of inflammation in nonalcoholic fatty liver disease. PLoS One 2012;7:e30668.

15 Huugen D, Xiao H, van Esch A, et al. Aggravation of anti-myeloperoxidase antibodyinduced glomerulonephritis by bacterial lipopolysaccharide: role of tumor necrosis factor-alpha. Am J Pathol 2005;167:47-58. 
16 Shiri-Sverdlov R, Wouters K, van Gorp PJ, et al. Early diet-induced non-alcoholic steatohepatitis in APOE2 knock-in mice and its prevention by fibrates. J Hepatol 2006;44:732-41.

17 Lumeng CN, DelProposto JB, Westcott DJ, et al. Phenotypic switching of adipose tissue macrophages with obesity is generated by spatiotemporal differences in macrophage subtypes. Diabetes 2008;57:3239-46.

18 Swirski FK, Libby P, Aikawa E, et al. Ly-6Chi monocytes dominate hypercholesterolemia-associated monocytosis and give rise to macrophages in atheromata. J Clin Invest 2007;117:195-205.

19 Drechsler M, Megens RT, van Zandvoort M, et al. Hyperlipidemia-triggered neutrophilia promotes early atherosclerosis. Circulation 2010;122:1837-45

20 Görgens A, Radtke S, Möllmann M, et al. Revision of the human hematopoietic tree: granulocyte subtypes derive from distinct hematopoietic lineages. Cell Rep 2013;3:1539-52.

21 Kerr MA, Stocks SC. The role of CD15-(Le(X))-related carbohydrates in neutrophil adhesion. Histochem J 1992;24:811-26.

22 Amanzada A, Malik IA, Nischwitz M, et al. Myeloperoxidase and elastase are only expressed by neutrophils in normal and in inflamed liver. Histochem Cell Biol 2011;135:305-15.

23 Miller JC, Brown BD, Shay T, et al. Deciphering the transcriptional network of the dendritic cell lineage. Nat Immunol 2012;13:888-99.

24 Rensen SS, Bieghs V, Xanthoulea S, et al. Neutrophil-derived myeloperoxidase aggravates non-alcoholic steatohepatitis in low-density lipoprotein receptor-deficient mice. PLoS One 2012;7:e52411.

25 Kolaczkowska E, Kubes P. Neutrophil recruitment and function in health and inflammation. Nat Rev Immunol 2013:13:159-75.

26 Nagareddy PR, Kraakman M, Masters SL, et al. Adipose tissue macrophages promote myelopoiesis and monocytosis in obesity. Cell Metab 2014;19:821-35.

27 Cao X, Zhang W, Wan T, et al. Molecular cloning and characterization of a novel CXC chemokine macrophage inflammatory protein-2 gamma chemoattractant for human neutrophils and dendritic cells. J Immunol 2000;165:2588-95.
28 Zhang L, Ran L, Garcia GE, et al. Chemokine CXCL16 regulates neutrophil and macrophage infiltration into injured muscle, promoting muscle regeneration. Am J Pathol 2009;175:2518-27.

29 De Filippo K, Dudeck A, Hasenberg M, et al. Mast cell and macrophage chemokines CXCL1/CXCL2 control the early stage of neutrophil recruitment during tissue inflammation. Blood 2013;121:4930-7.

30 Woehrl B, Klein M, Rupprecht T, et al. CXCL16 contributes to neutrophil recruitment to cerebrospinal fluid in pneumococcal meningitis. J Infect Dis 2010;202:1389-96.

31 Li J, Gao J, Yan D, et al. Neutralization of chemokine CXCL14 (BRAK) expression reduces $\mathrm{CCl} 4$ induced liver injury and steatosis in mice. Eur J Pharmacol 2011;671:120-7.

32 Wehr A, Baeck C, Ulmer F, et al. Pharmacological inhibition of the chemokine CXCL16 diminishes liver macrophage infiltration and steatohepatitis in chronic hepatic injury. PLoS One 2014;9:e112327.

33 Mei J, Liu Y, Dai N, et al. Cxcr2 and Cxcl5 regulate the IL-17/G-CSF axis and neutrophil homeostasis in mice. J Clin Invest 2012;122:974-86.

34 Zhou SL, Dai Z, Zhou ZJ, et al. Overexpression of CXCL5 mediates neutrophil infiltration and indicates poor prognosis for hepatocellular carcinoma. Hepatology 2012;56:2242-54.

35 Rouault C, Pellegrinelli V, Schilch R, et al. Roles of chemokine ligand-2 (CXCL2) and neutrophils in influencing endothelial cell function and inflammation of human adipose tissue. Endocrinology 2013;154:1069-79.

36 Marenholz I, Heizmann CW, Fritz G. S100 proteins in mouse and man: from evolution to function and pathology (including an update of the nomenclature). Biochem Biophys Res Commun 2004;322:1111-22.

37 Ryckman C, Vandal K, Rouleau P, et al. Proinflammatory activities of S100: proteins S100A8, S100A9, and S100A8/A9 induce neutrophil chemotaxis and adhesion. J Immunol 2003;170:3233-42. 